Division of Social Science

The Hong Kong University of Science and Technology

Working Papers in the Social Sciences, No. 12

\title{
The Rise of Manufacturing Towns: Externally Driven Industrialization and Urban Development in the Pearl River Delta of China
}

by

Irene Eng

Division of Social Science

Hong Kong University of Science and Technology

Clear Water Bay

Kowloon, Hong Kong

20 May 1997

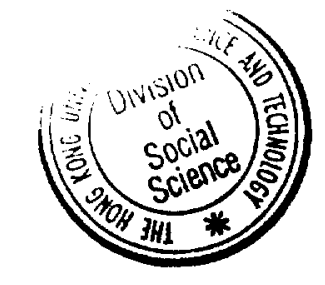


The Rise of Manufacturing Towns:

\title{
Externally Driven Industrialization and Urban Development in the Pearl River Delta of China
}

\author{
Irene Eing \\ Division of Social Science \\ Hong Kong University of Science and Technology \\ Clear Water Bay \\ Hong Kong
}

Forthcoming, International Journal of Urban and Regional Research 
Abstract This paper examines the forces that shape recent urban development in the economically most prosperous region of China--the Pearl River Delta. It shows that economic reform since 1978 has accelerated the pace of industrialization in the region and thereby led to the rise of a growing number of new urban centers. While public policies of the government continue to play a central role in defining the patterns of urbanization, they are increasingly localized and heavily influenced by the imperative of promoting externally oriented economic growth. As a result, the prioritization of resource allocation for urban development is tilted toward the need of attracting and retaining foreign investment, and the formation of the emergent urban social space follows closely the interplay between the interests of dominant players in the increasingly marketized economic process. A major consequence of this is a segregation of urban life along the lines of international and domestic division of labor, where the benefits of urban development accrue differentially to various urban residents according to the relative scarcity of the economic factors that they possess. 


\section{Introduction}

Acceleration of urbanization is a major feature of the economic change in China since the start of reform in 1978. From 1978 to 1993, the percentage of permanent urban residents in the total population increased from $17.92 \%$ to 28.14\% (GJTJJ, 1994a:59), whereas the number of localities classified as "cities" doubled from 233 in 1981 to 570 in 1993 (GJTJJ, 1981:1, 1994a:3). Concurrent with the growth of cities is a transformation of the rural economy from a predominantly agricultural sector to a sector combining commercial agriculture and non-farm activities such as industry, construction, transportation, and services. Between 1978 and 1993 the share of output from non-farm activities in total rural output went up from $31.4 \%$ to $72.5 \%$ (GJTJJ, 1994b:146). Since 1983 the former sites of the people's communes have been turned into rural and urban townships (xiang zhen) that not only serve as the state's grassroots level administrative centers, but function as the nexus of commercialized and diversified economic activities and take on increasing features of urban places. In 1993, there was a total of 48,179 of such localities (GJTJJ, 1994a:327).

This paper explores some of the important driving forces behind the rapid urban development in post-Mao China. The focus of analysis centers on the Pearl River Delta (abbreviated as PRD hereafter) in the southern province of Guangdong which, with a growth of GDP and gross industrial output at the average annual rates of $13.9 \%$ and $21 \%$ respectively for the period of 1979 - 
1993, leads the nation in the creation and growth of economic output (GDSTJ, 1994:54, 492-493; GJTJJ, 1994a:35). Situated in the vicinity of the estuary of the Pearl River and adjacent to Hong Kong and Macau, the PRD encompasses twenty-eight cities and counties, including one provincial capital and two special economic zones (Huang, 1995:17). In 1993, the region covered $23.2 \%$ of the surface area and made up $31.2 \%$ of the population of Guangdong, but accounted for $46.5 \%$ of the total number of urban townships, $47.45 \%$ of the nonagricultural population, $60.24 \%$ of the GDP, $66.22 \%$ of the export, and $81.68 \%$ of the savings by urban and rural residents of the province (GDSTJJ, 1994:146, 163; GDSTJJ \& ZGGSYHGDFH, 1994:8-9). From 1980 to 1993, the relative size of non-agricultural residents in local population rose from $28.5 \%$ to $41.8 \%$ (GDSTJJ, 1994:123; GDSTJJ \& ZGGSYHGDFH, 1994:8-9), making the PRD one of the most urbanized regions in China.

The phenomenal economic growth in the PRD has received broad attention. The region is hailed in media accounts as the spearhead of China's economic transformation (e.g., Worthy, 1992; Brudvig, 1993). It is also regarded by some academic studies as having the potential of leading Guangdong to become the fifth "Asian dragon" (e.g., Vogel, 1989; Sung et al., 1995). This paper looks beyond such general accounts of economic prosperity and relates its major contributing factors to an important but little discussed issue: how the emergent urban social spaces are formed in the region. 
Specifically, it investigates what orients the prioritization of resource allocation for recent urban development and shapes the distribution of the resultant benefits among local urban residents.

The main thrust of my analysis draws on the argument made by Scott (1988) that in modern capitalist economy the form of urban development hinges closely on the logic of production and the dynamics of division of labor. I propose that, although China can hardly be categorized as a capitalist economy despite the expansion of market and the growth of non-state economic elements, a parallel can be found between the essence of Scott's argument and what has taken place in urban China: Urban development is shaped in large part by the interplay between the interests of the dominant players in the economic game.

In the PRD, such players include officials of local governments that exert significant influence over the allocation of resources and economic opportunities, and foreign investors who mainly come from Hong Kong and possess two key factors for local economic growth--capital and access to international market. Structural changes in the form of decentralization and marketization during the reform have realigned the interests of local government officials from the implementation of centrally imposed decrees and policies to the development of local economies which relies heavily on foreign-invested, export-oriented economic entities. What attracts foreign investors is a supply of cheap labor and land and a favorable and flexible regulatory environment. To create and sustain 
these conditions, local governments have adopted measures that permit and regulate the inflow of migrant labor from outside the region and improve infrastructure facilities and social services needed for labor-intensive manufacturing. The result is a growth of industries and a rise and expansion of many new urban settlements clustered around the loci of manufacturing activities.

The pattern of urban development in these settlements, however, is characterized by a disparity in urban resource allocation among different groups of urban residents based on the relative scarcity of the economic factors that they possess. Most developed are the facilities and amenities catering to foreigners' needs in investment and consumption, which to a great extent are also utilized by well-to-do local residents, including government officials. What lags behind is the provision of public goods for ordinary urban residents situated at the lower rungs of the local work-force, such as education, low and middle income housing, public transport, health care, and environmental protection. Moreover, migrant workers, who constitute the bottom layer of the labor market but make up a large part of the local work force, are excluded from much of the urban life outside the workplace. They are denied permanent local resident status and the related entitlements, and social services catering to their basic needs are minimally developed. This differentiation in the distribution of the gains of urban development and the resultant segregation of urban life along the 
lines of international and domestic division of labor reflect the varying influence of different groups of urban residents (including sojourners from Hong Kong) over the increasingly marketized economic process and the formation of the new urban social space. They also add to many emergent urban problems, which pose a challenge to further economic growth and urbanization in the region.

In section 2 , I highlight the changes brought about by the reform in Guangdong province and explore how such changes affect the orientation of public policies on economic development. Section 3 examines how resources are allocated for urban development in the PRD. Section 4 analyzes the segregation of urban social space between different groups of urban residents. Section 5 summarizes major findings and discusses their implications.

\section{Reform and local governments' economic policy orientation}

Despite its long commercial tradition, Guangdong province had only a lack-lustre record of economic development before 1978. Under the central planning system, it was given low priority in resource allocation, mainly because of its relatively weak industrial foundation and the central leadership's concern about its geographical proximity to Hong Kong and Taiwan, which in Mao's view were bases for external hostile forces to subvert the communist regime (Vogel, 1989). In 1978, Guangdong's per capita national income was 320 yuan, very close to the national average of 313 yuan. In 1980, the industrial sector 
accounted for only $36.3 \%$ of the province's national income, much lower than the national average of 48.92.\% (GJTJJ, 1994a:20-21, 33; GDSTJJ, 1994:50, 70). However, in 1993 per capita national income of the province rose to 3,910 yuan, way above the national average of 2,100 yuan; and the much expanded industrial sector contributed $52.8 \%$ of the province's national income, exceeding the national average of $51.69 \%$ (ibid.).

Such drastic change in a rather short span of time is a result of the adoption of the "reform and opening to the outside world" policy since 1978. Economic reform has changed the incentives for government officials and economic actors, and reoriented their actions from implementation of centrally issued administrative commands to the search for opportunities for locally based economic growth. Increasing interactions with foreign economic elements, on the other hand, have created and broadened avenues for the inflow of investment and technology and for the expansion of linkages with international markets, thereby forging a close tie between the interests of dominant local and foreign players.

The major structural changes brought about by the economic reform in Guangdong are represented by two concurrent processes: decentralization and marketization. They were started in July 1979 when the central authority, in an attempt to make the province both a testing ground and a show case of China's new economic policy, granted it "special policies and flexible measures," which 
contained two core components (ZGGDSWBGT, 1992). First, the traditional practice of centralized, unified control over provincial revenue and spending was replaced with an arrangement that required the provincial government to remit to the central treasury fixed amounts of revenue according to annual targets specified for a five-year period starting from 1980, with any surplus above the targets left at the disposal of the provincial government. Second, the provincial government was given increasing decision-making authority over a wide range of economic issues, including planning, investment, price control, economic regulations, foreign economic relations, and wage and labor.

To take advantage of the opportunities ushered in by the restructuring of fiscal and administrative relations with the central government, the provincial government had to rely on enhanced efforts to increase revenue collection at lower levels of government, which ultimately hinged upon the revenue producing capabilities of economic organizations under their respective jurisdictions. Such a dependence relationship led to a chain reaction. Since the early 1980 s the provincial government has subcontracted out revenue targets to city or county governments through various revenue sharing schemes, and delegated to them increasing decision-making authorities over economic activities; this has in turn been duplicated between counties or cities and their subsidiary townships (Zhang and Shi, 1992). Between public enterprises and their supervising bodies in the government, profit-sharing has replaced total 
extraction of enterprise surplus by the latter; and considerable autonomy in decision-making has been granted to enterprises which have now grown out of the shadow of mandatory government planning and carry out their activities for and through market exchange (Liang and $\mathrm{Wu}, 1994)$.

Under the restructured authority relations in the state apparatus, local officials' interests are closely tied to the economic activities under their purview. Their performance (and the related position security and career advancement) is increasingly measured in terms of their ability to fulfill the revenue targets specified in the fiscal contract, rather than according to non-economic criteria such as ideological commitment and political conformity, which were emphasized under the pre-reform system (Vogel, 1989). Also, their income is directly tied to the growth of local revenue, especially that from the economic entities that they run. In Shunde, for example, each township government has formed an economic development corporation as the holding company of township enterprises. Headed by top township officials and operated as profit centers, such corporations contribute a proportion (3-5\%) of the growth in their subsidiary enterprises' net output to the bonus fund of top township officials (Wang, 1992:37). In addition, local officials also make various informal personal gains from the investment that they undertake with discretionary funds known as "extra-budgetary" and "self-raised" revenues (Huang, 1995). A major consequence of the fiscal contract system is a decline of the significance of 
centrally allocated resources in capital supply. In 1980, 49\% of Guangdong's capital investment was appropriated by the central authority; in 1990, the figure declined to $4 \%$ (YCWB, 1 July 1992). Because of their discretion in defining the direction of the investment under their purview, local officials can channel part of the resources to items that they can use for private consumption free of charge (such as cars, telephone, recreational facilities, and hostels), and to favored parties that can offer kick-backs. With the deepening of decentralization, therefore, localities have become the nexus of dominant local interests, which depends very much on the growth of market-oriented economic activities.

Parallel to the restructuring of economic relations since 1978 is a diversification of the sources of capital. In this regard, Guangdong has capitalized on what in part led to its low status in the pecking order of the prereform resource allocation system, i.e., its geographical proximity to Hong Kong and its extensive ties with overseas Chinese. It is claimed that, other than those in Hong Kong, Macau, and Taiwan, there are over 20 million overseas Chinese around the world, about $70 \%$ of whom have ancestral roots in Guangdong (Guan and Zhu, 1992:51). Because of geographical proximity and the cultural, kinship and language ties between the province and Hong Kong, and because of the gradual liberalization of government policies toward foreign capital (Vogel, 1989; Shirk, 1994), Guangdong (and the PRD in particular) has become a major 
destination for the outflow of capital from the British colony where since the mid 1970s rising labor and land costs have posed a major challenge to the predominantly labor-intensive manufacturing industries (FOHKI, 1991). From 1980 to 1993 , foreign direct investment (FDI) actually utilized in Guangdong increased from US\$123.2 million to US\$ 7.5 billion (GDSTJJ, 1994:303). During the same period, the output from subcontracting activities originated from abroad increased from US\$8.9 million to US\$ 6.5 billion, which together with the output from FDI firms accounted for $62 \%$ of Guangdong's export in 1993 (GDSTJJ, 1994:304). While 80-90\% of the foreign investment in the PRD comes from Hong Kong, it is also the first or final destination of more than $80 \%$ of the export of the Delta (Huang, 1995:40), giving rise to the phenomenon called "qiandian houchang"--meaning "store in the front (Hong Kong) and factory in the backyard (Guangdong)."

A major gain made by local governments from foreign invested entities is the collection of taxes (after the initial period of exemption and reduction) and fees which total 38 items in 5 categories (Huang, 1995:341). In subcontracting arrangements, for example, foreign manufacturers pay a processing fee to the local governments that own the factory facilities used to process orders from abroad. This has become a major source of revenue for many local governments in the PRD. From 1979 to 1991, the local governments in Dongguan collected over two billion US dollars of processing fees from 
enterprises subcontracting from abroad (Yan, 1993:72). Rent for land use paid by foreign investors is another major source of local government revenue. In 1993, the rent for the use of industrial sites and the sales of land use right for real estate development generated 11 billion yuan for local governments in Guangdong. This is equivalent to $49.57 \%$ of the budgetary revenue of the governments in that year, making land revenue the "second budget" of local governments (Huang, 1995:144).

Because of the importance of foreign invested entities to local governments, and because of the increasing competition between different localities to outbid one another for the inflow of resources and outperform one another economically, government officials are keen to attract foreign investors to their localities (Vogel, 1989). This concern is manifested in their approach toward urban development.

\section{Prioritization of resource allocation for urban development}

To appeal to foreign investors, local governments in the PRD have adopted various measures to make the economic and policy environments of their localities attractive to foreign investors. This has important implications to urban development. As government policies tilt toward the need to attract and sustain foreign investment, the allocation of resources and opportunities for urban development is prioritized accordingly. Projects and activities closely 
related to such a need are vigorously promoted, whereas those with no such bearing receive much less attention. Thus, while extensive production-related infrastructural facilities and amenities accommodating foreign investors have been built up rapidly, the provision of public goods for ordinary citizens, which appears to assume secondary importance to the operations of foreign invested entities, lags far behind.

In Dongguan, the city government has set up a task force to integrate the work of different decision-making bodies involved in matters related to foreign economic relations. As a result, subcontracting agreements and foreign direct investment projects could be reviewed and approved within a week (Wang, 1992:10). In Shunde, $80 \%$ of the large investment projects involving foreign capital are claimed to be arranged with the help of the township governments which also have played a key role in negotiating and signing deals with foreign investors (Huang, 1995:23-24). Following the example of Special Economic Zones established in the early 1980s to attract foreign investment with tax concessions and regulatory flexibility (Shirk, 1994), local governments in the PRD have set up similar policy enclaves to offer special favorable treatments to foreign investors. In the districts and counties of Guangzhou alone, there were 18 special industrial development zones set up by local governments by the end of 1990 (Huang, 1992:188). The total number of such zones in the PRD amounted to 39 by mid 1992 (Liu and Hu, 1994:10). 
Concentrating resources on the development and improvement of infrastructural facilities represents another major area of local governments' efforts to attract foreign capital to their localities. Between 1981 and 1990 the city government of Nanhai invested over 1.2 billion yuan in infrastructure projects, resulting in the construction of about 300 kilometers of local roads, 20 new bridges, 4 power plants, and an imported telephone exchange system of 56,000 lines (Liang and Wu, 1994:103-104). In Dongguan, from 1980 to 1991 over six billion yuan were invested in transportation, energy, communication, and land formation for plant site construction (ZGGDSWBGT, 1992:95). In the PRD as a whole, preparation and construction have been under way for 22 airports (Huang, 1995:15).

As the PRD's economy grows, large amounts of resources are poured into real estate development. This, however, is mainly fuelled by foreign capital and tailored to the demand of buyers from Hong Kong where property prices are many times higher than those in the PRD. In 1993, for example, $89 \%$ and $70 \%$ of the real estate investments in Dongguan and Huizhou came from foreign investors (Huang, 1995:142). In the late 1980s, $80 \%$ of the private housing in Zhongshan was owned by overseas Chinese (ZGGQCSBWH, 1989: 382). In $1991,70 \%$ of the commercial housing in Guangzhou was purchased by foreign capital entities (Shi and Qiu, 1993:8). As the chief clientele of real estate development consists of foreign investors in the PRD, resource allocation 
follows their demand. In 1990, nearly one third of the hotels catering to foreigners in China were located in Guangdong; and of the 5 five-star and 10 four-star hotels in the PRD, all but one were joint ventures with foreign capital (Huang, 1992:332). According to incomplete statistics reported in early 1995, over 100 high class residential developments were under construction in the PRD (Huang, 1995:143). In the urban development plan of Dongguan announced in the early 1990 s, three primary targets were set: expanding the old city center, constructing a number of high-class, large commercial complexes, and building a number of high-class tourist hotels and recreational facilities (Shi and Qiu, 1993:51).

Overshadowed by the real estate development catering to foreign demand, housing facilities for ordinary urban residents have only limited resources to draw upon. As the prices for properties built by foreign developers are not capped by the government, the greater profit margin for high class real estate has attracted enormous capital into speculation, driving up housing prices and draining the resources for the development of medium and low class housing. Prior to 1988 when real estate development in Shenzhen was opened to foreigners, property prices increased at the rate of less than $20 \%$ per year. After that, the rate shot up to over 70\% (Huang, 1992:177). Although urban living space in the PRD averaged on a per capita basis has significantly increased since the early 1980s (ZGGDSWBGT, 1992), much of the basic housing needs of 
average income earners remains to be addressed (GDSJHWYH, 1995:112-116). A conservative estimate suggests that at least one million units of subsidized and low-profit housing would be needed for the bottom quartile of permanent urban residents in the region who have the poorest housing conditions (CTFRHXJLJJH, 1993:83). This is the segment to which the least resources have been allocated for housing development. In the city of Nanhai, for example, in 1993 only 1,520 square meters of subsidized and low profit housing were constructed, whereas 331,700 square meters of commercial housing were completed (GDNJS, 1994:146). Low priority for the housing needs of low and medium income residents appears to be a major factor behind such disparity. The city's 20 "key construction projects" in 1994 include four bridges, one highway, one telephone expansion project, three commercial complexes, three factories, four luxury housing estates, three office buildings, and one stadium (GDNJS, 1994:6-7).

The situation is similar in other areas of public good provision. In Dongguan, between 1978 and 1984 the average shares of government budgetary spending on "economic construction" and "cultural activities, education, health and scientific research" were $28 \%$ and $55.6 \%$ respectively; in the period of 1985-1992 when full-scale economic reform was carried out and large amount of foreign capital poured in, the figures changed to $36.41 \%$ and $38.1 \%$ respectively (DGTJJ, 1991:486-489; DGTJJ, 1992: 347). As the region is 
rapidly industrialized and urbanized, environmental decay also accelerates, especially in the new manufacturing centers. Acid rain has become a major problem in the PRD (Chen et al., 1993), making its air among the most polluted in the world. In 1993, the frequencies of acid rain in Foshan and Jiangmen were $84 \%$ and $83 \%$ respectively (Huang, 1995:409). The level for the region as a whole has exceeded $50 \%$ (Chen, 1995). Underground water is heavily polluted too. Dali and Pingzhou, for example, are two newly developed industrial towns in Nanhai. Their underground water has been so polluted that the two townships have had to shut down their water plants and rely on a less developed town for water supply (Chen el al., 1993:109). The 1994-1995 White Paper on Social Development prepared by the Guangdong Planning Commission reports that in 1994 only $6.7 \%$ of urban sewage water was treated and "most of the rivers passing through cities and towns are seriously polluted and heavy urban noise pollution has become a major public hazard" (GDSJHWYH, 1995:107, 122).

The skewed pattern of resource allocation for urban development can also be seen from a comparison between four major cities in the PRD--Zhongshan, Dongguan, Shunde, and Nanhai--and other Chinese cities of similar administrative status. Designated as cities in 1984, 1985, 1992 and 1992 respectively, they are newly industrialized urban centers drawing heavily on foreign capital, and are often referred to as the PRD's four "tigers" with the 
fastest rate of economic growth and urban development in the reform. In 1993, they accounted for $26.6 \%$ of the population, $54.95 \%$ of the GDP, and $68.3 \%$ of the export in the PRD (GDSTJJ, 1994:87, 90).

\section{Table 1 about here}

Despite their impressive economic growth, the supply of public goods to urban residents in these cities has not kept pace with the rapid industrialization and development of production-related infrastructural facilities and profit-making services. This can be seen from the figures in Table 1, which indicate that items of a public good nature (e.g., public transport, urban green belt, and health service) are much less developed relative to items that have direct pertinence to foreign investment or profit-making (roads, power supply, telecommunication, etc.). Note all the figures in the table are derived by using permanent local residents as the denominator. If the large numbers of migrant labor in these cities are included, the per capita indicators will be much lower.

It should be noted that foreigners are not the only group of people who drive and benefit from this type of urban development. Government officials in economically developed localities have enriched themselves through financial rewards in various forms, including bonuses and the use of newly added public assets for private consumption (Vogel, 1989). Suburban residents in selected localities have thrived on the rent paid by foreign investors for the use of their farm land as factory or real estate sites (Wang and Wang, 1995). Unlike other 
local residents, the high earnings of these two groups enable them to resort to private goods to fill in the gaps left open by the under-supply of public goods. This brings up the next issue, namely, the segregation of urban life among different groups of urban residents.

\section{Segregation of urban life}

As a result of the active economic role played by local governments and the influx of foreign capital, non-farm economic activities have flourished in the PRD and led to the rise and growth of many new urban centers. From 1978 to 1993, 16 counties were elevated to city status; from 1982 to 1993 , the total number of townships increased from 132 to 1,321 (Huang, 1995:12). However, not only is resource allocation for urban development in the region skewed toward certain externally driven imperatıves, but social life in the emergent urban centers is segregated among urban residents along the lines of international and domestic division of labor.

Hong Kong investors, who provide the bulk of the foreign capital in the PRD, are the most privileged group in the new urban centers. While they share broad economic interests with local elites--especially local officials, their interaction with locals is mainly confined to the work place and the market place. They mostly live in enclave estates specifically built for foreigners, commute frequently between Hong Kong and their second (or third) residence 
in the PRD, and raise their families in Hong Kong. Their social ties with locals are mainly maintained through kinship rather than developed through social bonding based on spatial proximity and shared community life. Even among the locals who have relatives in Hong Kong, there is evidence that close interaction between the two groups is limited (He, 1991: 117). While various cultural products through visual, audio, and printed media from Hong Kong have enormously influenced the local cultural life and to a great extent defined and homogenized its contents (He, 1991:166-167), they tend not to narrow, but to sharpen an awareness of, the division in social identity because of the impossibility of local residents' sharing in the mainstay of Hong Kong people's social life built on quite a different economic foundation beyond the border.

Among permanent local residents, government officials and enterprise managers are the most well-off in terms of income growth, largely because of their important roles in access control and in the regulation and organization of economic activities (Vogel, 1989). This social stratum is joined by some former peasants who have prospered mainly on the huge rent for the farm land that was leased to them by the state after decollectivization in the early 1980 s but has now been sub-leased to foreign invested entities. They are given a sizeable portion of the rent while sharing in the community benefits (such as pension, insurance, and scholarship for children attending college) that are expanded by local governments with part of the remaining portion of the rent 
(ZGDGSWXCB, 1993:4-5). In a way, this reduces an urban-rural divide in social and economic status, which was created and sustained before the reform as a result of a redistributive policy to reward those undertaking activities more directly related to industrial development while systematically excluding rural residents from the more privileged life of urban residents (Oi, 1991).

But it should be noted that such uplifting effect is most evident mainly among a small portion of the population in the PRD, especially in the towns located along the two major high-ways between Guangzhou and Zhuhai (Macau) and between Guangzhou and Shenzhen (Hong Kong) (Chen et al., 1990:77). Even there variation in land revenue among different localities is quite significant (DGSRMZBGS \& DGSDAG, 1993:97). For local residents in the majority of townships in the PRD, rent income and community welfare benefits based on local government revenue are still limited, and wage income continues to constitute their main source of living (Yan, 1993). Although their earnings from the workplace have enormously increased as a result of the economic growth fuelled by foreign investment, they remain in the lower rungs of the local social hierarchy because of their lower economic status in the new division of labor. Social divisions between locals, however, are overshadowed by that between locals and migrant workers whose presence in the region has drastically changed the composition of the local labor force since the mid 1980s.

A major attraction of the PRD to foreign investors is the availability of 
large numbers of cheap labor. Most of this labor force comes from other regions of Guangdong and, increasingly, other provinces ( $\mathrm{Li}$ and Shao 1995). In the late 1970s when China re-opened its door to the outside world, large numbers of people in Guangdong emigrated to Hong Kong to join their relatives, creating a major labor shortage, especially in urban areas (Huang, 1995:222). To address this problem and supply abundant labor for foreign investors, in the early 1980 s governments at various levels in the province gradually relaxed urban household registration control and allowed rural residents to enter cities to undertake industrial, commercial, and service activities (Xu and Li, 1990). Because of its much faster pace of economic growth, since the mid 1980s the PRD has become a major attraction for migrant labor from other provinces, especially Guangxi, Hunan, and Sichuan (Fan 1996). To cope with the influx of migrant labor and regulate the emergent labor market, local governments have imposed strict regulations on employment and residence while relaxing restrictions on entry. Migrant workers wishing to stay at a locality are required to obtain (with a fee) a temporary residence card from the local public security office and have it renewed periodically (every 6 or 12 months); also, those wishing to be employed locally have to obtain work permit from local labor departments (Wang and Wang, 1995).

There are no complete statistics on migrant labor in the province or the $\mathrm{PRD}$; and estimates vary, ranging from a few million to ten million (Huang, 
1995:54, 222). Foreign capital firms, especially those in labor-intensive sectors such as plastics, garments, and toys, are the main employers of migrant labor. It is estimated that by 1991 about three million workers were employed by Hong Kong capital firms in the PRD, most of whom were migrant s orkers (Huang 1995:13). In the province as a whole, a 1992 study reports that over five million people were employed by foreign capital firms (Guan and Zhu, 1992:199). In some major centers of externally oriented manufacturing, the proportion of migrant labor in the local labor force has come close to or even exceeded that of local residents. According to a 1995 study, $86 \%$ of the workforce in Dongguan consisted of migrant workers (Wang and Wang, 1995). The figure reported in a 1994 survey is $57.96 \%$ for Foshan and $41.84 \%$ for Huizhou (ZGQNB, March 18 1994).

A striking feature of the newly developed manufacturing towns in the PRD is the sharp contrast between the working and living conditions of migrant workers and those of permanent local residents (ZGGQCSBWH, 1989; Liang and Wu, 1994). Most migrant laborers work for long hours on low-pay jobs under poor working conditions in manufacturing, construction, and sanitary services. Many of them are paid in the form of piece rate wage without job security, and few have medical insurance. They live in overcrowded factory quarters or in shanty-towns and ghettos built or expanded on the fringe of the town centers. On the other hand, permanent local residents mostly work on 
cleaner and better paid jobs, with a broader range of fringe benefits, including housing, pension, and medical and unemployment insurance. Between migrant workers and locals there is little social interaction outside the workplace (He, 1991; Wang and Wang, 1995).

The main barrier to reducing or eliminating the difference in treatment between local and migrant workers consists in the restrictions almost unanimously imposed by local governments on the right of permanent local residence (Woon, 1993). It is extremely difficult for migrant workers to become permanent settlers because only under two circumstances can they obtain permanent local resident status: marrying a permanent local resident and purchase of local housing. Two major factors are behind the adoption of this policy.

First, allowing migrant workers to settle permanently would threaten the supply of cheap labor in foreign invested entities. Granting permanent resident status to migrant workers would give them certain non-market bargaining power to push for raising the level of accepted standard of treatment. With permanent resident status, workers who have migrated from elsewhere and settled down locally would be more determined to press local governments and employers to improve working conditions (including labor rights) and raise their level of fringe benefits comparable to that of native permanent local residents. Short of such change, labor productivity would tend to fall because of the widening gap 
between the expectations and treatments of workers using the same frame of reference. Replacing such workers with new settlers can hardly solve the problem because of the likelihood of the same demand being raised by the latter before long. Also, it would be more difficult for firm owners to lay off settled residents than migrants, especially in large numbers, in that as compared to the latter the former tend to assign more weight to retaining their current jobs and thus have greater resolve in protracted fight with employers. Consequently, the existing pattern of international division of labor would have to be sustained and reproduced at a much higher cost to the capital suppliers whose profit margin depends heavily on a minimization of labor cost.

Second, allowing migrant workers to stay permanently would entitle them to the welfare benefits of local residents and thus bring down--at least in the short run--the standard of living of local residents. Also, the need to expand social services for new settlers and their families would impose a major burden on local governments and drain the resources that could otherwise be used for activities that can bring more direct private gains to local officials. Public security and labor departments of local government would face a dwindling of the revenue from the application and renewal fees paid by temporary workers for permits to stay and work.

Ironically, this policy has a major down-side as well. A great trade-off is the outflow of the wage income earned by migrant labor. Because of the 
manual nature of their work the income of migrant workers is generally lower than that of permanent local residents (Wang and Wang 1995). In view of the dim prospect for permanent settlement, migrant workers keep their local consumption to a minimal level and send their savings to their homes outside the PRD (ZGQNB, March 8 1994). In Dongguan, it is estimated that the money remitted by migrant workers to their homes amounts to over three billion yuan a year, whereas the total retail volume of the city was 4.8 billion yuan in 1994 (Wang and Wang, 1995). While this adds to the problem of underdeveloped service activities catering to the needs of this group of people, it also funnels part of the gains from economic development out of the PRD.

Another problem is inequality and the rising tension and conflict between locals and migrants, and between foreign capital representatives and labor. Its main source consists in the unfavorable differential treatment received by migrant workers and the tolerance of local governments toward exploitative labor practices in foreign capital firms (e.g., SCMP, 3, 5 and 14 July 1994). The perception of being exploited by locals (and employers) is found to be widespread among many migrants, especially those from other provinces (He, 1991:190). Open confrontation between migrant workers and management has become a common scene of the economic life in the PRD. From 1989 to 1993, the number of reported labor disputes involving migrant workers in Foshan totalled 1,964, and the figure for Huizhou during the period of 1990-1993 is 947 
(ZGQNB, 8 March 1994). In 1993 alone, over 5,000 labor disputes were reported in foreign capital firms in the region as a whole (Huang, 1995:15). These conflicts not only raise social justice concerns, but pose a threat to economic efficiency because they may undermine cooperation and thus productivity. High turn-over among labor has also become a major problem to foreign capital firms, especially those requiring higher skills (Wang and Wang, 1995). In addition, high mobility of labor weakens the incentive for firms to invest in human resource development, hampering economic upgrading.

A third problem has to do with urban social order and the increasing strain faced by local state administration. The influx of predominantly young migrants into urban and urbanizing areas, job insecurity, difficulty of permanent settlement into local community, and tension between locals and migrants have all contributed to spawning an increase of criminal activities in the PRD, including the growth and spread of such "social vices" as drugs, prostitution, and gambling. In the city of Zhongshan, the percentage of "serious cases" among all criminal cases increased from $1.7 \%$ in 1979 to $40.1 \%$ in 1988 , whereas the total number of criminal cases handled by the local public security office per year increased from less than 300 in 1983 to 3,824 in 1988 (ZGGQCSBWH, 1990:418-419). Migrants were identified as a major source of the rise in criminal offense. In Nanhai, for example, $84.6 \%$ of the criminal offenses in 1993 were committed by migrants (GDNJS, 1994:58). 
In the face of large numbers of migrant population, traditional social control mechanisms based on stable household registration and the danwei system (Walder, 1986) can no longer function effectively. Local governments have to rely more and more on the police to keep order. Many localities have spent large amount of resources hiring civilian security forces to assist law enforcement (Wang and Wang, 1995; ZGDGSWXCB, 1993). Other problems in local state administration include increasing difficulties in the maintenance of urban public facilities and the planning for further urban development (GDNJS, 1994:88; GDSJHWYH, 1995:110). The presence of large numbers of migrants makes it difficult to keep up the conditions of streets and sanitary facilities. The haphazard construction and growth of shanty-towns and substandard housing used by migrant workers, plus the worsening situation of environmental pollution, also pose new challenges to urban planning and public health.

To address these problems effectively, local governments have to change the existing policy toward migrant labor, which is no longer determined nationally (Huang, 1995; Fan, 1996). But this involves two major risks. One is the migration of foreign capital to other parts of China in the event of falling profit. Since the financial and career rewards to local officials are locality specific, their stake tends to be greater than foreign investors'. The other is the loss of local popular support in that local residents who have gained from the policy desire to see a continuation of the status quo. Despite their lack of direct 
policy input in local governments, their overwhelming opposition to a particular policy could complicate local politics and make its proponents vulnerable to attacks by rivals or opportunistic peers. Also, their withdrawal from cooperation with grassroots officials could paralyse the implementation of local government policies. Since the cost of handling these risks appears to be high, and since there are still short-term gains for local officials, little has been done to bring down the settlement barriers to migrants.

\section{Discussion}

In the reform era, the driving force of industrialization also shapes the way resources are allocated for urban development and the way the emergent urban social space is formed in the PRD. Such an urbanization process bears a remarkable resemblance to that before the reform: They both follow the logic of production much more closely than that of consumption and social interaction. What is changed, though, is the mechanism whereby the impact of production is manifested. Before 1978, it was the need to hold down consumption in order to finance centrally planned industrial development, and the need to maintain political control by restricting social mobility, that oriented the state's administrative commands in resource allocation and led to the stratification of urban life (Whyte and Parish, 1984; Riskin, 1987). Since the late 1970s, it is the need to attract foreign capital and combine it with other 
economic factors through decentralized profit-seeking activities that has shaped the course of urban development and defined the pattern of segregated urban life in the PRD.

Market force is a major factor that conditions recent urban development, in that relative scarcity in factor supply and market access determines who the dominant players in the new economic game are and whose interests are attended to first and foremost. The skewness in the approach taken by local governments toward urban development is mainly a result of the asymmetric relationship among major suppliers of economic factors. Those that command the most wanted resources in economic activities tend to be those whose needs are most fully accommodated in the emergent urban centers. Unlike those in some other regions in Guangdong or other provinces of China, industrialization in the PRD has been powered mainly by factor markets located outside the region and situated under different demand-supply conditions. A result of this is that foreign investors, who possess two key factors to local economic growth-capital and external market connections, have more direct and indirect impact on the process of urbanization than regular local residents despite the fact that by and large the former are only occasional residents in the region. In contrast, workers, especially migrant workers, who are almost in unlimited supply, have little influence in this regard.

Although market power constitutes the basis of foreign capital's 
significant influence on production and urban development, such power can hardly be brought into full play without being combined with the actions of local governments. As the gate-keepers of their local economies and the chief allocators of local resources, government officials in different localities are indispensable partners of foreign investors. In the reform era, their interest bases are reconfigured and, consequently, there have been major changes in the orientation of public policies on urban development. They are increasingly driven by locally based and marketized economic interests rather than the imperative to carry out centrally defined ideological agendas, by the concerns for revenue maximization and growth rather than equity, and by short-term gains and expediencies rather than long-term calculations.

What brings the two groups of dominant players together is the convergence of their interests. This close relationship not only outweighs local officials' relationship with ordinary local residents. By providing alternative and more bountiful sources of private gains, it also makes local officials less dependent on the provision of public goods that they share with ordinary local residents. On the other hand, it should be emphasized that among localities within the PRD there is enormous variation in the degree of dependence on foreign capital. The economic significance of foreign capital appears to be much greater in such centrally located cities as Dongguan than in cities like Sihui situated on the fringe of the PRD. A hypothesis that may be derived from 
an account of this broad spectrum of reality is that the higher the dependence of local economic development on foreign capital, the more likely the kind of skewness in urban development as discussed above.

Related to this is the way social relations in urban life have been transformed. Under the pre-reform central planning system there was enormous disparity between rural and urban residents in social and economic status because of the resource allocation policy biased against the rural sector (Riskin, 1987; Oi, 1991). In the reform, significant economic gains made by peasants in many parts of the PRD have drastically reduced such an urban-rural divide. As discussed above, some rural residents have even become richer than many ordinary urban residents because of the enormous rent revenue accruing to the farm land used by foreign investors for industrial and real-estate development. But in the social space of the emergent town centers, which is shared not only by permanent urban residents but increasingly by rural residents undertaking non-farm activities, social life has been stratified along the lines of international and domestic division of labor. Key decision-makers, including government officials and foreign investors, are at the top of the urban hierarchy. Next to them are local business elites and rent collectors. Further down are ordinary permanent local residents who are mostly middle or lower middle level employees. At the bottom are migrant workers who constitute the mainstay of the local work force but are excluded from much of the social life. The lower 
in the hierarchy, the greater the number of people, and the less developed the urban facilities.

A noteworthy aspect of such an urban hierarchy is that those whose market bases are outside the region--foreign investors and migrant workers--have minimal involvement in community activities of the new urban centers. Social interactions outside the economic process are largely confined to groups originating from different social spaces. This intra-urban divide is further deepened by an institutionalized exclusion of migrant workers from permanent settlement into the local community, which reflects the interests of dominant players in the economic game. The segregation of urban life in the region is thus not simply a result of the effects of occupational differentiation or the volatility and fluidity of factor markets. It is shaped by a division of economic interests along the same line of division of labor in a market where the relationship among the participants is heavily unbalanced. Therefore, it may be more appropriate to characterize the production-driven, socially segregated urban settlements as "manufacturing towns" than "urban communities."

An irony of this type of urban development is that it has sown the seeds of many problems for further economic growth and urbanization, including deterioration of the ecological environment and urban facilities, underdevelopment of human resources, increase of tension and conflict both in and outside the work place, and decay of the local state apparatus' capacity to 
govern. How and to what extent the interests of the dominant players in the new economic game are affected or offset by these problems, how these problems are tackled, and who bears the cost of fixing them are among the issues of interest for future research. 


\section{References}

Brudvig, L.A. (1993) The fifth dragon. The China Business Review July-August, 14-23.

Caituan faren haxia jiaolu jijin hui (CTFRHXJLJH). (1993) Zhujiang sanjiao zhou touzi huanjing (Investment environment in the Pearl River Delta).

Taipei.

Chen, L., et al. (eds.) (1990) Shunde xian xianyu yanjiu (A territorial study of the county of Shunde). Zhongshan daxue xuebao bianji bu, Guangzhou.

. (eds.) (1993) Nanhai shi shehui jingii fazhan yanjiu yu guihua (A study on the social and economic development and planning in the city of Nanhai). Guangdong ditu chuban she, Guangzhou.

. (1995) Zhujiang sanjiao zhou jingji fazhan yu huanjing wenti yanjiu (A study on the economic development and environmental issues in the Pearl River Delta). Zhujiang sanjiaozhou jingji (The Pearl River Delta Economy) 2, 17-20.

Dongguan shi renmin zhenfu bangong shi, Dongguanshi danan guan (DGSRMZBGS \& DGSDAG). (1993) Dongguan gaige kaifang jishi ( $A$ portrayal of Dongguan's economic reform and opening to the outside world). Dongguan.

Dongguan tongji ju (DGTJJ). (1991) Dongguan tongji nianjian 1991 (Statistical yearbook of Dongguan 1991). Dongguan.

. (1992) Dongguan tongji nianjian 1992 (Statistical yearbook of Dongguan 1992). Dongguan.

Fan, C.C. (1996) Economic opportunities and internal migration: a case study of Guangdong province, China. Professional Geographer 48(1): 28-45.

Federation of Hong Kong Industries (FOHKI). (1991) Hong Kong's industrial investment in the Pearl River Delta. Hong Kong.

Guan, Q. and H. Zhu. (eds.) (1992) Guangdong duiwai maoyi yanjiu (Studies on Guangdong's foreign trade). Huanan ligong daxue chuban she, Guangzhou. 
Guangdong nianjian she (GDNJS). (1994) Nanhai nianjian 1994 (Nanhai yearbook 1994). Guangzhou.

Guangdong sheng jihua weiyuan hui (GDSJHWYH). (1995) Shehui fazhan baipi shu: Guangdong shehui fazhan huigu yu zhanwang (White Paper on Social Development: Guangdong's Social Development in Retrospect and Prospect). Guangdong renmin chuban she, Guangzhou.

Guangdong sheng tongji ju (GDSTJJ). (1994) Guangdong tongji nianjian 1994. (Statistical Yearbook of Guangdong 1994). Guangdong tongji chuban she, Guangzhou.

Guangdong sheng tongji ju, and Zhongguo gongshang yihang guangdong fenhang (GDSTJJ \& ZGGSYHGDFH). (1994) Guangdong quyu jingji tongji ziliao huibian 1980-1993 (A Collection of Regional Statistics of Guangdong 1980-1993). Guangzhou.

Guojia tongji ju (GJTJJ). (1981) Zhongguo tongji nianjian 1981 (Statistical Yearbook of China 1981). Zhongguo tongji chuban she, Beijing.

. (1994a) Zhongguo tongji nianjian 1994 (Statistical Yearbook of China 1994). Zhongguo tongji chuban she, Beijing.

. (1994b) Zhongguo nongcun tongji nianjian 1994. (Rural Statistical Yearbook of China 1994). Zhongguo tongji chuban she, Beijing.

(1994c) Zhongguo chengshi tongji nianjian 1993-1994. (Urban Statistical Yearbook of China 1993-1994). Zhongguo tongji chuban she, Beijing.

He, Z. (ed.) (1991) Zhujiang sanjiaozhou jizhen yu jumin (Towns and residents in the Pearl River Delta). Huanan ligong daxue chuban she, Guangzhou.

Huang, H.Q. (ed.) (1992) Zhu jiang san jiao zhou jing ji fa zhan hui gu yu qian zhan (Economic Development of the Pearl River Delta: A Retrospect and Prospects). Zhongshan daxue chuban she, Guangzhou.

. (1995) (Zhu jiang san jiao zhou jing ji fa zhan xin tou shi (New Perspectives on the Economic Development in the Pearl River Delta). Zhongshan daxue chuban she, Guangzhou.

Li, S. and Y. Shao. (1995) Guangdong sheng renkou qianyi: dalu, daiwan he 
xianggang jingji hezuo dui renkou de yingxiang (Population migration in Guangdong province: the impact of the economic cooperation of the maniland, Taiwan, and Hong Kong on population). Renkou yanjiu (Population research) 19(5): 38-44.

Liang, M. and G. Wu. (1994) (eds.) Jianshe you zhongguo te se she hui zhuyi daolu de tansuo (Exploring a socialist road with Chinese characteristics). Zhonggong zhongyang danxiao chuban she, Beijing.

Liu, Y. and A. Hu. (1994) Zhujiang sanjiao zhou dagong jingshang luyou zhinan (A guide to work, travel, and business in the Pearl River Delta). Guangdong sheng ditu chuban

Oi, J. (1991) Reform and urban bias in China. Journal of Development Studies, 129-148.

Riskin, C. (1987). China's political economy: the quest for development since 1949. Oxford University Press, Oxford.

Scott, A.J. (1988) Metropolis. University of California Press, Berkeley.

Shi, J. and C. Qiu. (1993) Zhujiang sanjiao zhou fandichan touzi zhinan (A guide to real estate investment in the Pearl River Delta). Guangdong renmin chuban she, Guangzhou.

Shirk, S. L. (1994) How China opened its door. The Brookings Institution, Washington, DC.

South China Morning Post (SCMP)

Sung, Y, P. Liu, Y. R. Wong and P. Lau. (1995) The fifth dragon: the emergence of the Pearl River Delta. Addison Wesley Publishing Company, Hong Kong and New York.

Vogel, E. (1989) One step ahead in China: Guangdong under reform. Harvard University Press, Cambridge, MA.

Walder, A.G. (1986) Communist neo-traditionalism: work and authority in Chinese industry. University of California Press, Berkeley.

Wang, L. (1992) Lijing tu zhi: guangdong jingji fazhan jiemi (Working hard: the 
key to Guangdong's economic development). Guangdong keji chuban she, Guangzhou.

Wang, H. and X. Wang. (1995) Jingying yimin yu xinxing da chengshi zhanlue (Elite migration and strategies for newly developed large cities). Canyue wengao (Working papers) No. 95-4. Beijing.

Whyte, M. K. and W. Parish. (1984) Urban life in contemporary China. University of Chicago Press, Chicago.

Woon, Y. (1993) Circulatory mobility in post-Mao China: temporary migrants in Kaiping county, Pearl River Delta region. International Migration Review 27, no. 3, 578-604.

Worthy, F.S. (1992) Where capitalism thrives in China. Fortune March 19, 71 75.

Xu, X. and S. Li. (1990) China's open door policy and urbanization in the Pearl River Delta region. International Journal of Urban and Regional Research Vol 14 No 1, 49-69.

Yan, W. (1993) Zhujiang sanjiao zhou jingji fazhan moshe yu celue fenxi (A study of the economic development patterns and policies in the Pearl River Delta). Guangdong luyou chuban she, Guangzhou.

Yangcheng wanbao (YCWB) (Evening News of the Goat City)

Zhang, Z. and Z. Shi. (eds.) (1992) Gaige kaifang zhong de guangdong jingji (Guangdong's economy in reform and opening). Zhonghan daxue chuban she, Guangzhou.

Zhonggong dongguan shiwei xuanchuan bu (ZGDGSWXCB). (1993) Silu yu kuayue--Dongguan kaige kaifang toushi (An indepth look at Dongguan's reform and opening to the outside world). Guangdong renmin chuban she, Guangzhou.

Zhonggong guangdong shenwei banggongting (ZGGDSWBGT). (1992) Guangdong gaige kaifang qishilu (The examples set by Guangdong's reform and opening to the outside world). Renmin chuban she, Beijing.

Zhongguo guoqing congshi bianwei hui (ZGGQCSBWH). (1989) Bai xian shi 
jingji shehui diaocha: Zhongshan juan ( $A$ general survey of 100 counties and cities: the Zhongshan volume). Zhongguo da baike quanshi chuban she, Beijing.

Zhongguo qingnian bao (ZGQNB) (China Youth Daily) 
Table 1. Selected Indicators of Economic and Urban Development, 1993

\begin{tabular}{|c|c|c|c|c|c|}
\hline $\begin{array}{l}\text { indicators } \\
\text { (per } 10,000 \\
\text { persons) }\end{array}$ & $\begin{array}{l}\text { all } \\
\text { sub- } \\
\text { provincial } \\
\text { cities* }\end{array}$ & Zhongshan & Dongguan & Shunde & Nanhai \\
\hline $\begin{array}{l}\text { gross } \\
\text { industrial \& } \\
\text { agricultural } \\
\text { output (million } \\
\text { yuan) }\end{array}$ & $-\cdots-$ & 188 & 148 & 236 & 211 \\
\hline $\begin{array}{l}\text { foreign } \\
\text { capital } \\
\text { utilized } \\
(10,000 \text { US } \$)\end{array}$ & 23.94 & 314.75 & 570.57 & 150.38 & 100.73 \\
\hline $\begin{array}{l}\text { export volume } \\
(10,000 \text { US } \$)\end{array}$ & 33.99 & 739.46 & 905.14 & 853.97 & 474.74 \\
\hline $\begin{array}{l}\text { retail of } \\
\text { consumer goods } \\
(10,000 \text { yuan })\end{array}$ & $1,492.11$ & $3,058.44$ & $3,953.09$ & $3,607.12$ & $3,995.57$ \\
\hline $\begin{array}{l}\text { number of } \\
\text { post offices }\end{array}$ & .87 & .41 & 1.16 & ---- & -.--- \\
\hline $\begin{array}{l}\text { number of } \\
\text { telephones }\end{array}$ & 373.33 & $1,277.77$ & $1,165.32$ & $---\cdot$ & $-\cdots$ \\
\hline $\begin{array}{l}\text { volume of } \\
\text { electricity } \\
\text { usage }(10,000 \\
\text { kw/hrs })\end{array}$ & $1,340.47$ & $1,520.93$ & $2,835.89$ & $1,390.57$ & $1,285.77$ \\
\hline $\begin{array}{l}\text { water supply } \\
(10,000 \text { tons })\end{array}$ & 84.73 & 72.74 & 41.88 & 142.26 & 74.77 \\
\hline
\end{tabular}


(continued)

\begin{tabular}{llllll}
$\begin{array}{l}\text { number of } \\
\text { buses for } \\
\text { public }\end{array}$ & 1.32 & 1.23 & 0.94 & 3.02 & 0.23 \\
transport & & & & & \\
$\begin{array}{l}\text { surface area } \\
\text { of paved } \\
\text { roads }(\mathrm{sq} / \mathrm{m})\end{array}$ & 2.16 & 2.05 & 2.35 & 6.84 & 6.51 \\
$\begin{array}{l}\text { length of } \\
\text { sewage pipes } \\
\text { (km) }\end{array}$ & 1.43 & 1.61 & .90 & 6.20 & 1.24 \\
$\begin{array}{l}\text { size of green } \\
\text { belt within } \\
\text { city (ha) }\end{array}$ & 7.78 & 3.62 & 3.08 & 2.94 & 0.39 \\
$\begin{array}{l}\text { number of } \\
\text { hospitals }\end{array}$ & .49 & .058 & .27 & .16 & .17 \\
$\begin{array}{l}\text { number of } \\
\text { hospital beds }\end{array}$ & 32.40 & 11.21 & 35.56 & 27.60 & 15.35 \\
$\begin{array}{l}\text { number of } \\
\text { doctors }\end{array}$ & 20.41 & 12.25 & 14.56 & 18.45 & 15.04 \\
\hline
\end{tabular}

Sources: GJTJJ (1994c); GDSTJJ (1994); GDSTJJ \& ZGGSYHGDFH (1994).

* Note: Cities included in this column have administrative status similar to that of the four cities in the Pearl River Delta. Provincial capitals, centrally administered cities, and special economic zones are excluded. 